\title{
Glycemic Outcomes in Adults With Type 2 Diabetes Participating in a Continuous Glucose Monitor-Driven Virtual Diabetes Clinic: Prospective Trial
}

Amit R Majithia ${ }^{1}$, MD; Coco M Kusiak ${ }^{2}$, MS; Amy Armento Lee ${ }^{2}$, MS; Francis R Colangelo ${ }^{3}$, MD; Robert J Romanelli ${ }^{4}$, PhD; Scott Robertson ${ }^{2}$, RN; David P Miller ${ }^{2}$, MS; David M Erani ${ }^{5}, \mathrm{MD}$; Jennifer E Layne ${ }^{6}, \mathrm{PhD}$; Ronald F Dixon ${ }^{6}$, MD; Howard Zisser², MD

\footnotetext{
${ }^{1}$ Department of Medicine and Department of Pediatrics, University of California San Diego School of Medicine, La Jolla, CA, United States

${ }^{2}$ Verily Life Sciences, South San Francisco, CA, United States

${ }^{3}$ Allegheny Health Network, Monroeville, PA, United States

${ }^{4}$ Sutter Health, Palo Alto, CA, United States

${ }^{5}$ Onduo Professionals, PC, Newton, MA, United States

${ }^{6}$ Onduo, LLC, Newton, MA, United States
}

\section{Corresponding Author:}

Amit R Majithia, MD

Department of Medicine and Department of Pediatrics

University of California San Diego School of Medicine

Biomedical Research Facility II (3A19)

9500 Gilman Drive

La Jolla, CA, 92093

United States

Phone: 18588220727

Email: amajithia@ucsd.edu

\begin{abstract}
Background: The Onduo virtual diabetes clinic (VDC) for people with type 2 diabetes (T2D) combines a mobile app, remote personalized lifestyle coaching, connected devices, and live video consultations with board-certified endocrinologists for medication management and prescription of real-time continuous glucose monitoring (RT-CGM) devices for intermittent use.

Objective: This prospective single-arm study evaluated glycemic outcomes associated with participation in the Onduo VDC for 4 months.

Methods: Adults aged $\geq 18$ years with T2D and a baseline glycated hemoglobin (HbA1c) of $\geq 8 \%$ to $\leq 12 \%$ were enrolled from 2 primary care centers from February 2019 to October 2019. Participants were asked to engage at $\geq 1$ time per week with their care team and to participate in a telemedicine consultation with a clinic endocrinologist for diabetes medication review. Participants were asked to use a RT-CGM device and wear six 10-day sensors (total 60 days of sensor wear) intermittently over the course of 4 months. The primary outcome was change in HbA1c at 4 months from baseline. Other endpoints included change in weight and in RT-CGM glycemic metrics, including percent time <70, 70-180, 181-250, and >250 mg/dL. Changes in blood pressure and serum lipids at 4 months were also evaluated.
\end{abstract}

Results: Participants ( $\mathrm{n}=55)$ were 57.3 (SD 11.6) years of age, body mass index 33.7 (SD 7.2), and 40\% (22/55) female. HbA1c decreased significantly by $1.6 \%$ (SD $1 \% ; P<.001)$. When stratified by baseline HbA1c of $8.0 \%$ to $9.0 \%(\mathrm{n}=36)$ and $>9.0 \%(\mathrm{n}=19)$, HbA1c decreased by $1.2 \%$ (SD $0.6 \% ; P<.001)$ and $2.4 \%$ (SD 1.3\%; $P<.001$ ), respectively. Continuous glucose monitoring-measured $(\mathrm{n}=43$ ) percent time in range (TIR) $70-180 \mathrm{mg} / \mathrm{dL}$ increased by $10.2 \%$ (SD 20.5\%; $P=.002$ ), from $65.4 \%$ (SD $23.2 \%$ ) to $75.5 \%$ (SD 22.7\%), which was equivalent to a mean increase of 2.4 hours TIR per day. Percent time $181-250 \mathrm{mg} / \mathrm{dL}$ and $>250 \mathrm{mg} / \mathrm{dL}$ decreased by $7.2 \%$ (SD 15.4; $P=.005$ ) and 3.0\% (SD 9.4; $P=.01$ ), respectively. There was no change in percent time $<70 \mathrm{mg} / \mathrm{dL}$. Mean weight decreased by $9.0 \mathrm{lb}$ (SD 10.4; $P<.001$ ). Significant improvements were also observed in systolic blood pressure, total cholesterol, low-density lipoprotein cholesterol, and triglycerides $(P=.04$ to $\mathrm{P}=<.001)$.

Conclusions: Participants in the Onduo VDC experienced significant improvement in HbA1c, increased TIR, decreased time in hyperglycemia, and no increase in hypoglycemia at 4 months. Improvements in other metabolic health parameters including 
weight and blood pressure were also observed. In conclusion, the Onduo VDC has potential to support people with T2D and their clinicians between office visits by increasing access to specialty care and advanced diabetes technology including RT-CGM.

Trial Registration: ClinicalTrials.gov NCT03865381; https://clinicaltrials.gov/ct2/show/NCT03865381

(J Med Internet Res 2020;22(8):e21778) doi: 10.2196/21778

\section{KEYWORDS}

continuous glucose monitoring; telemedicine; telehealth; digital health; type 2 diabetes; HbA1c

\section{Introduction}

In recent years, there has been a dramatic increase in telehealth programs for the management of diabetes [1]. These programs have the potential to support about 34 million individuals with diabetes in the United States and may play a larger role in future diabetes care, given the expected increase in the incidence and prevalence of diabetes in the next decade and beyond [2]. Telehealth programs for diabetes typically include a smartphone app, connected devices such as blood glucose meters, and remote coaching that may be automated or provided by a live health coach. Current telehealth programs, however, do not address the limitations of the traditional health care model of diabetes management: limited access to endocrinologists, specialist education, and advanced diabetes management technology.

There is growing recognition that advanced technology, including continuous glucose monitoring (CGM) devices, can play an essential role in diabetes care for people with type 2 diabetes (T2D), regardless of their treatment regimen [3-7]. The Onduo Virtual Diabetes Clinic (VDC), a telehealth model for people with T2D, is unique in incorporating CGM in its care model. Availability of live video consultations with board-certified endocrinologists for medication management and the ability to remotely prescribe CGM devices are also unique components of the VDC. Real-world evidence suggests that participation in the VDC is associated with significant improvement in $\mathrm{HbA}_{1 \mathrm{c}}$ [8] and a significant reduction in diabetes distress [9]. Here we report outcomes of a prospective single-group assignment trial, examining changes in $\mathrm{HbA}_{1 \mathrm{c}}$ in adults with T2D after 4 months of participation in the Onduo VDC.

\section{Methods}

\section{Study Objective}

The primary objective of this prospective single-arm study was to evaluate the change in $\mathrm{HbA}_{1 \mathrm{c}}$ in adults with $\mathrm{T} 2 \mathrm{D}$ after 4 months of participation in the Onduo VDC. Additional outcomes included change in glycemic metrics from CGM (mean glucose, coefficient of variation, and percent time $<70 \mathrm{mg} / \mathrm{dL}, 70$ to 180 $\mathrm{mg} / \mathrm{dL}$ [time in range (TIR)], 181 to $250 \mathrm{mg} / \mathrm{dL}$, and $>250$ $\mathrm{mg} / \mathrm{dL}$ at 4 months from baseline.Changes in weight, blood pressure (BP), and serum lipids-namely, total cholesterol, high-density lipoprotein (HDL) cholesterol, triglycerides, low-density lipoprotein (LDL) cholesterol, cholesterol/HDL ratio, and non-HDL cholesterol-were also evaluated at 4 months from baseline.

\section{Participants}

Participants were enrolled from 2 primary care networks-Allegheny Health Network, Pittsburgh, PA and Sutter Health Palo Alto Medical Foundation, Palo Alto, CA. Inclusion criteria were as follows: $\geq 18$ years of age or older, confirmed diagnosis of $\mathrm{T} 2 \mathrm{D}, \mathrm{HbA}_{1 \mathrm{c}}$ level $8.0 \%$ and $12.0 \%$, willingness to use a blood glucose meter and CGM device, and own a smartphone. Exclusion criteria were as follows: use of an insulin pump; pregnant or breastfeeding; malignant cancer in the previous 12 months; any solid organ transplant; end-stage (stage 4 or 5) renal disease or dialysis; liver failure; cystic fibrosis; chronic heart failure (Class C, D); diabetes-related pancreatic failure; current use of a blood thinner; and self-reported adhesive allergy. All participants provided written informed consent. The study protocol and consent forms were approved by the Western Institutional Review Board and registered with ClinicalTrials.gov NCT03865381.

\section{Protocol}

Baseline and final assessments were conducted in-person at the designated study sites including, physical measures, blood draws, and questionnaires. The intervention was conducted remotely through the Onduo VDC.

\section{Virtual Diabetes Clinic Participation}

The Onduo VDC telehealth program for people with T2D has been previously described $[8,9]$. In brief, the program combines mobile app technology, remote personalized lifestyle coaching from Certified Diabetes Care and Education Specialists (CDCES) and health coaches, and connected blood glucose meters and real-time continuous glucose monitoring (RT-CGM) devices. Live video consultations with board-certified endocrinologists are available as needed for medication management in addition to prescribing CGM. Participants interact with their care team and are sent educational materials by messaging through the app. Participants use the app to track data relevant to diabetes care (such as, blood glucose readings and CGM data) and to log medication use, physical activity, meal photos, and other information.

In this study, participants were asked to engage $\geq 1$ time per week with their health coach or care team and to participate in a telemedicine consultation with VDC endocrinologists. All participants were mailed a RT-CGM device-Dexcom G6 (Dexcom) - for intermittent use. Participants were asked to wear six 10-day sensors (total 60 days of sensor wear) intermittently over the course of 4 months. Initial period of CGM device-wearing lasted for 20 days (consisting of 2 sensors worn back to back). Subsequently, the remaining 4 sensors were deployed in a 10-days "on" and 11-days "off" cycle. Sensor 
glucose data were used by the care team for coaching and monitoring and as an educational feedback loop to assist participants in associating their glucose levels with their diet, lifestyle, and other factors to optimize diabetes self-management. Glucose data were also used by the VDC endocrinologists for medication management. During the 4-month period, additional CGM sensor wear may have been requested by VDC endocrinologists to evaluate the efficacy of medication changes and monitor impact on blood glucose.

\section{Statistical Analysis}

A sample size of 60 participants was selected to provide $90 \%$ power to detect a $0.5 \%$ decrease in $\mathrm{HbA}_{1 \mathrm{c}}$ at 4 months from baseline (primary outcome) using a 2-sided test with $\alpha=.05$, after assuming $20 \%$ loss to follow-up. RT-CGM glycemic metrics, including mean glucose, coefficient of variation, and percent time $<70 \mathrm{mg} / \mathrm{dL}, 70$ to $180 \mathrm{mg} / \mathrm{dL}, 181$ to $250 \mathrm{mg} / \mathrm{dL}$, and $>250 \mathrm{mg} / \mathrm{dL}$ ) were calculated from an initial 10-day period within 30 days of enrollment to a 10-day follow-up period $>90$ days from enrollment, with a data sufficiency requirement of $>70 \%$ of possible readings. All outcomes were evaluated by paired $t$ test except for ranges $<70 \mathrm{mg} / \mathrm{dL}$ and $>250 \mathrm{mg} / \mathrm{dL}$, which were evaluated by Wilcoxon signed rank test. Nominal significance levels ( $P$ values) are presented with statistical significance defined as $P<.05$. All statistical analyses were performed using Python 3.6.7.

\section{Results}

A total of 60 participants enrolled in the study, and 92\% (55/60) completed the 4-month intervention. Reasons for withdrawal included protocol violations/non-compliance $(n=3)$ and withdrawal of consent $(n=2)$. Out of 55 participants who completed the study, 89\% (49/55) had a medication change. Baseline demographic and clinical characteristics of the participants are presented in Table 1. 
Table 1. Participant demographics at baseline.

\begin{tabular}{|c|c|}
\hline Variables & Values \\
\hline Female, n (\%) & $22(40)$ \\
\hline Age (years) mean (SD) & $57.3(11.6)$ \\
\hline Weight (lb) mean (SD) & $218.7(59.7)$ \\
\hline $\mathrm{BMI},{ }^{\mathrm{a}}$ mean $(\mathrm{SD})$ & $33.7(7.2)$ \\
\hline Baseline $\mathrm{HbA}_{1 \mathrm{c}},(\%)$ mean $(\mathrm{SD})$ & $8.9(1.0)$ \\
\hline Systolic blood pressure (mm Hg) mean (SD) & $132.1(15.8)$ \\
\hline Diastolic blood pressure $(\mathrm{mm} \mathrm{Hg})$ mean $(\mathrm{SD})$ & $80.7(10.4)$ \\
\hline Total cholesterol (mg/dL) mean (SD) & $168.3(42.8)$ \\
\hline $\mathrm{HDL}^{\mathrm{b}}$ cholesterol $(\mathrm{mg} / \mathrm{dL})$ mean $(\mathrm{SD})$ & $40.4(9.1)$ \\
\hline $\mathrm{LDL}^{\mathrm{c}}$ cholesterol $(\mathrm{mg} / \mathrm{dL})$ mean $(\mathrm{SD})$ & $100.1(36.5)$ \\
\hline Non-HDL cholesterol (mg/dL) mean (SD) & $128.0(42.70)$ \\
\hline Total cholesterol/HDL ratio, mean (SD) & $4.4(1.4)$ \\
\hline Triglycerides (mg/dL) mean (SD) & $236.7(194.3)$ \\
\hline \multicolumn{2}{|l|}{ Diabetes medications, $\mathbf{n}(\%)$} \\
\hline 0 & $0(0)$ \\
\hline 1 & $6(11)$ \\
\hline 2 & $21(38)$ \\
\hline$\geq 3$ & $28(51)$ \\
\hline \multicolumn{2}{|l|}{ Type of diabetes medications, $n(\%)$} \\
\hline Alpha glucosidase inhibitor & $1(2)$ \\
\hline Biguanide & $46(84)$ \\
\hline DPP-4 ${ }^{\mathrm{d}}$ inhibitor & $10(18)$ \\
\hline GLP-1 ${ }^{\mathrm{e}}$ analogue & $14(25)$ \\
\hline Insulin & $20(36)$ \\
\hline SGLT2 $2^{f}$ inhibitor & $20(36)$ \\
\hline Sulfonylurea & $30(55)$ \\
\hline Thiazolidinedione & $2(4)$ \\
\hline Lipid-lowering medications & $44(80)$ \\
\hline
\end{tabular}

${ }^{\mathrm{a} B M I}$ : body mass index.

${ }^{\mathrm{b}}$ HDL: high-density lipoprotein.

${ }^{\mathrm{c}} \mathrm{LDL}$ : low-density lipoprotein.

${ }^{\mathrm{d}}$ DPP-4: dipeptidyl peptidase-4.

${ }^{\mathrm{e}}$ GLP-1: glucagon-like peptide-1.

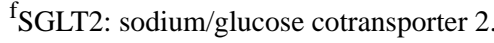

\section{Change in HbA1c}

$\mathrm{HbA}_{1 \mathrm{c}}$ decreased significantly by $1.6 \%$ (SD $1 \% ; P<.001$ ), from

(Figure 1). When stratified by baseline $\mathrm{HbA}_{1 \mathrm{c}}$ of $8.0 \%$ to $9.0 \%$ $(\mathrm{n}=36)$ and $>9.0 \%(\mathrm{n}=19), \mathrm{HbA}_{1 \mathrm{c}}$ decreased by $1.2 \%(\mathrm{SD} 0.6 \%)$ $8.9 \%(\mathrm{SD} 1 \%)$ at baseline to $7.3 \%$ (SD $0.9 \%$ ) at 4 months and $2.4 \%$ (SD $1.3 \%$ ), respectively (both $P<.001$ ). 
Figure 1. Change in HbA1c at 4 months from baseline. ${ }^{*} P<.001$.

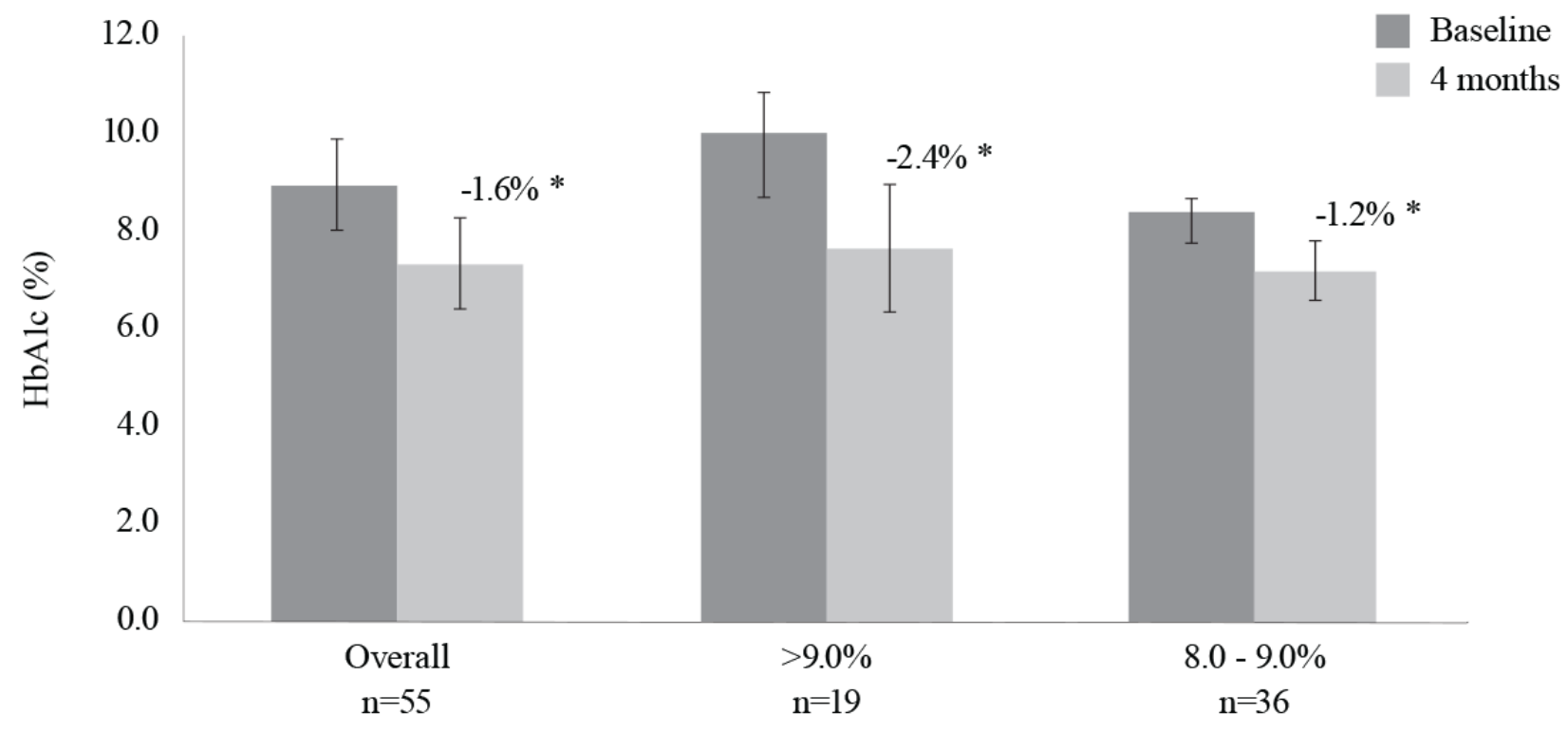

Baseline HbAlc Range

\section{CGM Device Use}

Out of 55 participants in the study, 78.2\% (43/55) met the criteria of follow-up CGM sensor-wear periods $>90$ days from baseline. Sensor-wear period was $94.8 \%$ (SD 8.2\%) of the time specified per protocol (60 days) in this cohort. CGM metrics $(n=43)$ are presented in Table 2 . The increase in percent time in range 70 to $180 \mathrm{mg} / \mathrm{dL}$ was equivalent to a mean increase of 2.4 hours TIR per day.

Table 2. Changes in CGM metrics at 4 months from baseline.

\begin{tabular}{lllll}
\hline Parameter & $\begin{array}{l}\text { Baseline } \\
\text { Mean (SD) }\end{array}$ & $\begin{array}{l}\text { Follow-up } \\
\text { Mean (SD) }\end{array}$ & \multicolumn{2}{l}{$\begin{array}{l}\text { Change } \\
\text { Mean (SD) }\end{array}$} \\
\hline $\begin{array}{l}\text { Mean glucose (mg/dL) } \\
\text { Coefficient of variation (\%) }\end{array}$ & $169.2(29.3)$ & $154.6(33.0)$ & $-14.6(27.5)$ & .001 \\
$\begin{array}{l}\text { Percent time (\%) } \\
\quad<70 \mathrm{mg} / \mathrm{dL}\end{array}$ & $24.5(4.9)$ & $22.9(5.5)$ & $-1.6(4.5)$ & .02 \\
70 to $180 \mathrm{mg} / \mathrm{dL}$ & & & $0.1(0.7)$ & .49 \\
181 to $250 \mathrm{mg} / \mathrm{dL}$ & $0.2(0.4)$ & $0.3(0.6)$ & $10.2(20.5)$ & .002 \\
$>250 \mathrm{mg} / \mathrm{dL}$ & $65.4(23.2)$ & $75.5(22.7)$ & $-7.2(15.4)$ & .005 \\
\hline
\end{tabular}

\section{Weight, BP, and Serum Lipids}

Change in weight, BP, and serum lipids at 4 months from baseline are presented in Table 3. Significant decreases were observed in weight, body mass index (BMI), systolic BP, total cholesterol, LDL cholesterol, total cholesterol/HDL ratio and triglycerides $(P=.04$ to $P<.001)$. 
Table 3. Change in BP and serum lipids at 4 months from baseline.

\begin{tabular}{|c|c|c|c|c|}
\hline Parameter & $\begin{array}{l}\text { Baseline } \\
\text { Mean (SD) }\end{array}$ & $\begin{array}{l}\text { Follow-up } \\
\text { Mean (SD) }\end{array}$ & $\begin{array}{l}\text { Change } \\
\text { Mean (SD) }\end{array}$ & $P$ value \\
\hline Weight (lb) ${ }^{\mathrm{a}}$ & $217.5(59.5)$ & $208.5(53.7)$ & $-9.0(10.4)$ & $<.001$ \\
\hline $\mathrm{BMI}^{\mathrm{ab}}$ & $33.6(7.2)$ & $32.2(6.5)$ & $-1.34(1.5)$ & $<.001$ \\
\hline Systolic BP ${ }^{\mathrm{ac}}(\mathrm{mm} \mathrm{Hg})$ & $132.4(15.8)$ & $128.0(16.6)$ & $-4.4(13.1)$ & .04 \\
\hline Diastolic BP $(\mathrm{mm} \mathrm{Hg})^{\mathrm{a}}$ & $80.5(10.5)$ & $79.8(10.5)$ & $-0.8(7.5)$ & 0.48 \\
\hline Total cholesterol (mg/dL) & $168.3(42.8)$ & $151.7(41.1)$ & $-16.6(46.0)$ & $<.001$ \\
\hline $\mathrm{HDL}^{\text {ad }}$ cholesterol, (mg/dL) & $40.4(9.1)$ & $40.0(10.9)$ & $-0.4(7.1)$ & .90 \\
\hline $\mathrm{LDL}^{\mathrm{ae}}$ cholesterol (mg/dL) & $100.1(36.5)$ & $93.6(31.9)$ & $-6.5(27.5)$ & .04 \\
\hline Total cholesterol/HDL Ratio & $4.4(1.4)$ & $3.9(1.3)$ & $-0.5(1.4)$ & .003 \\
\hline Triglycerides (mg/dL) & $236.7(194.30)$ & $193.0(163.2)$ & $-43.7(115.4)$ & .008 \\
\hline
\end{tabular}

${ }^{\mathrm{a}}$ For $\mathrm{n}=54$ ( 1 subject did not complete the 4-month assessment at the study site, but submitted results from an external laboratory).

${ }^{\mathrm{b}} \mathrm{BMI}$ : body mass index.

${ }^{\mathrm{c}} \mathrm{BP}$ : blood pressure.

${ }^{\mathrm{d}}$ HDL: high-density lipoprotein.

e LDL: low-density lipoprotein.

\section{Adverse Events}

There were no serious adverse events.

\section{Discussion}

In this prospective single-arm trial of the Onduo VDC, adults with T2D and suboptimal glycemic control experienced a statistically significant and clinically meaningful reduction in $\mathrm{HbA}_{1 \mathrm{c}}$ at 4 months. Analysis of RT-CGM metrics demonstrated a significant increase in TIR, decreased time in hyperglycemia, and found no increase in hypoglycemia. Participants also experienced significant decreases in weight, systolic BP, and serum lipids. Delivering RT-CGM devices, incorporating insights from intermittent RT-CGM use, and evaluating glycemic outcomes using RT-CGM data are unique aspects of the overall Onduo VDC care model for people with T2D.

Erhardt et al [4] and Vigersky et al [5] have reported on the use of intermittent RT-CGM in a population with T2D in a 52-week, two-arm, randomized controlled trial (RCT) that compared a 12-week active intervention of intermittent RT-CGM use to self-monitoring blood glucose. Similar to the present study, this RCT [4,5] also utilized Dexcom RT-CGM devices on an intermittent basis ( 2 weeks use, 1 week off) and measured short-term change in $\mathrm{HbA}_{1 \mathrm{c}}$. Participants in the RCT (RT-CGM group $n=50$ ) and the present study were predominately male, similar for age, baseline $\mathrm{HbA}_{1 \mathrm{c}}$ and insulin use. Health insurance coverage differed: RCT participants were military health care beneficiaries compared to a mainly commercially insured population in the present study. In addition, the present study integrated intermittent RT-CGM data in Onduo VDC's coaching and telemedicine care model, while limited information was reported regarding the use of RT-CGM data in the RCT. A mean decrease in $\mathrm{HbA}_{1 \mathrm{c}}$ of $1 \%$ was observed in the RCT RT-CGM group vs $1.6 \%$ in the present study, suggesting a potential additive or synergistic benefit of combining intermittent RT-CGM and telehealth in people with T2D. Interestingly, TIR at the final assessment was similar in the RCT intervention group and the present study, $75.3 \%$ and $75.5 \%$, respectively. During the 40-week follow-up period, RCT participants did not use RT-CGM, yet durable improvement in $\mathrm{HbA}_{1 \mathrm{c}}$ was observed at the 52-week follow-up assessment in the RT-CGM group compared with the self-monitoring blood glucose group. Similarly, the duration of our intervention was 4 months, and an evaluation of outcomes at 12-month outcomes is planned.

Previous studies of telehealth interventions in individuals with $\mathrm{T} 2 \mathrm{D}$ have reported reductions in $\mathrm{HbA}_{1 \mathrm{c}}$ ranging from $0.7 \%$ to $2.1 \%$ [10-14]. Some of these studies have also reported improvements in secondary outcomes such as weight, lipids, and BP, although results are variable [11,13-16]. Direct comparisons to prior telehealth studies are complicated by differences in participant demographics, length of intervention, program features, and method of reporting $\mathrm{HbA}_{1 \mathrm{c}}$, for example, directly measured vs estimated from fingerstick blood glucose readings. The magnitude of $\mathrm{HbA}_{1 \mathrm{c}}$ reduction in this prospective trial is consistent with that observed at an average of 4 months in a recently published retrospective analysis of 740 VDC participants [8]. Specifically, in participants with a baseline $\mathrm{HbA}_{1 \mathrm{c}} \geq 8 \%, \mathrm{HbA}_{1 \mathrm{c}}$ declined by $1.5 \%$ in the retrospective study and by $1.6 \%$ in the present study. In participants with baseline $\mathrm{HbA}_{1 \mathrm{c}}>9.0 \%, \mathrm{HbA}_{1 \mathrm{c}}$ declined by $2.3 \%$ in the retrospective study and $2.4 \%$, in this study.

Importantly, this is the first telehealth study in which participants with T2D were provided RT-CGM devices and changes in RT-CGM metrics beyond $\mathrm{HbA}_{1 \mathrm{c}}$ were quantified. Providing RT-CGM to participants in the VDC program supports individualized diabetes management in 2 ways. First, it improves self-management by showing participants how specific diet and 
lifestyle choices impact their blood glucose fluctuations. Second, rich information on glycemic variability that is best derived from CGM data provides information to VDC endocrinologists, pharmacists, nutritionists, CDCES, and health coaches to guide lifestyle and therapeutic interventions.

At a population level, assessing changes in RT-CGM-derived glycemic outcomes supplements $\mathrm{HbA}_{1 \mathrm{c}}$, offering additional insight into the impact of an intervention on diabetes management. Notably, the mean $10 \%$ increase in TIR observed in this study-equivalent to an increase of 2.4 hours per day-is considered a clinically meaningful increase [17]. Increased TIR is associated with lower vascular complication burden [5]. People with T2D report that TIR has at least as significant impact as $\mathrm{HbA}_{1 \mathrm{c}}$ has on their daily life [18]. The dual application of RT-CGM as a therapeutic and diagnostic tool is a unique strength of the Onduo VDC program and this study.

Limitations of our study include the sample size, duration of the intervention, and lack of a randomized control arm. It is important to note that some of the observed decrease in $\mathrm{HbA}_{1 \mathrm{c}}$ may be attributed to regression to the mean. Further studies are planned.

This prospective clinical trial of the Onduo VDC demonstrated improvements in glycemic outcomes in adults with suboptimally controlled T2D. Improvements in risk factors for diabetes complications, including weight, BP, and serum lipids were also observed.

\section{Acknowledgments}

The authors thank the study participants and Onduo clinical team, including the care leads and certified diabetes educators. We would like to thank John Schmucker and Anne Vermeulen for their leadership. We thank the staff at the participating research centers, particularly, Ashley Wilferd and the staff of the Allegheny Singer Research Institute of the Allegheny Health Network, Pittsburgh, PA; Elizabeth Mesghina and the staff of Sutter Health; and Palo Alto Medical Foundation Research Institute, Palo Alto, CA. We appreciate the efforts of the research and clinical teams at Verily Life Sciences, including Riddhi Kapoor, Maryam Yaghini, and Karina Brennecke. Funding for the study was provided by Onduo LLC, Newton, MA. Some of these data were presented at the 80th Scientific Sessions of the American Diabetes Association, A Virtual Experience, June 12-16, 2020.

\section{Authors' Contributions}

All authors contributed to the review of the report and approved the final version for submission. FRC, DME, and RJR contributed to the acquisition of data and all authors contributed to the interpretation of data. JEL developed the first draft of the manuscript. All authors contributed with a critical revision of the first and subsequent manuscript versions. RFD, CMK, AAL, ARM, DPM, $\mathrm{HZ}$, and SR contributed to the study design. ARM is the guarantor of this work and, as such, had full access to all the data in the study and takes responsibility for the integrity of the data and the accuracy of the data analysis.

\section{Conflicts of Interest}

ARM has received consulting fees from Onduo LLC. RFD and JEL are employees of Onduo LLC, a joint venture of Verily Life Sciences and Sanofi. CMK, AAL, HZ, and DPM are employees and shareholders of Verily Life Sciences. SR was an employee of Verily Life Sciences at the time the work was completed. DME is an employee of Onduo Professionals, PC, which provides clinical services to Onduo LLC. RJR and FRC report no conflicts of interest.

\section{References}

1. Levine BJ, Close KL, Gabbay RA. Reviewing U.S. connected diabetes care: the newest member of the team. Diabetes Technol Ther 2020;22(1):1-9. [doi: 10.1089/dia.2019.0273] [Medline: 31483160]

2. Centers for Disease Control and Prevention. National Diabetes Statistics Report, 2020. Atlanta, GA: Centers for Disease Control and Prevention, US Department of Health and Human Services; 2020. URL: https://www.cdc.gov/diabetes/pdfs/ data/statistics/national-diabetes-statistics-report.pdf [accessed 2020-08-11]

3. American Diabetes Association. 7. Diabetes Technology: Standards of Medical Care in Diabetes — 2020.. Diabetes Care 2020 Jan;43(Suppl 1):S77-S88. [doi: 10.2337/dc20-S007] [Medline: 31862750]

4. Ehrhardt NM, Chellappa M, Walker MS, Fonda SJ, Vigersky RA. The effect of real-time continuous glucose monitoring on glycemic control in patients with type 2 diabetes mellitus. J Diabetes Sci Technol 2011 May 01;5(3):668-675 [FREE Full text] [doi: 10.1177/193229681100500320] [Medline: 21722581]

5. Vigersky RA, Fonda SJ, Chellappa M, Walker MS, Ehrhardt NM. Short- and long-term effects of real-time continuous glucose monitoring in patients with type 2 diabetes. Diabetes Care 2012;35(1):32-38 [FREE Full text] [doi: 10.2337/dc11-1438] [Medline: 22100963]

6. Beck RW, Riddlesworth TD, Ruedy K, Ahmann A, Haller S, Kruger D, DIAMOND Study Group. Continuous glucose monitoring versus usual care in patients with type 2 diabetes receiving multiple daily insulin injections: a randomized trial. Ann Intern Med 2017;167(6):365-374. [doi: 10.7326/M16-2855] [Medline: 28828487]

7. Park C, Le QA. The effectiveness of continuous glucose monitoring in patients with type 2 diabetes: a systematic review of literature and meta-analysis. Diabetes Technol Ther 2018 Sep;20(9):613-621. [doi: 10.1089/dia.2018.0177] [Medline: $\underline{30095980]}$ 
8. Dixon RF, Zisser H, Layne JE, Barleen NA, Miller DP, Moloney DP, et al. A virtual type 2 diabetes clinic using continuous glucose monitoring and endocrinology visits. J Diabetes Sci Technol 2019 Nov 25:1932296819888662. [doi: 10.1177/1932296819888662] [Medline: 31762302]

9. Polonsky W, Layne J, Parkin C, Kusiak C, Barleen N, Miller D, et al. Impact of participation in a virtual diabetes clinic on diabetes-related distress in individuals with type 2 diabetes. Clin Diabetes 2020 Jun 12:cd190105-cd190106 [FREE Full text] [doi: $10.2337 / \mathrm{cd} 19-0105]$

10. Bollyky JB, Bravata D, Yang J, Williamson M, Schneider J. Remote lifestyle coaching plus a connected glucose meter with certified diabetes educator support improves glucose and weight loss for people with type 2 diabetes. J Diabetes Res 2018;2018:3961730 [FRE Full text] [doi: 10.1155/2018/3961730] [Medline: 29888288]

11. Quinn CC, Shardell MD, Terrin ML, Barr EA, Ballew SH, Gruber-Baldini AL. Cluster-randomized trial of a mobile phone personalized behavioral intervention for blood glucose control. Diabetes Care 2011;34(9):1934-1942 [FREE Full text] [doi: 10.2337/dc11-0366] [Medline: 21788632]

12. Bandi A, Larson M, Beattie J. MON-LB002 Diabetes Care Network: A telehealth based collaborative approach to scale endocrine expertise. Journal of the Endocrine Society 2019;3(Supplement_1):1-4. [doi: 10.1210/js.2019-MON-LB002]

13. Wang G, Zhang Z, Feng Y, Sun L, Xiao X, Wang G, et al. Telemedicine in the management of type 2 diabetes mellitus. Am J Med Sci 2017 Jan;353(1):1-5. [doi: 10.1016/j.amjms.2016.10.008] [Medline: 28104096]

14. Sun C, Sun L, Xi S, Zhang H, Wang H, Feng Y, et al. Mobile phone-based telemedicine practice in older chinese patients with type 2 diabetes mellitus: randomized controlled trial. JMIR Mhealth Uhealth 2019 Jan 04;7(1):e10664 [FREE Full text] [doi: 10.2196/10664] [Medline: 30609983]

15. Hallberg SJ, McKenzie AL, Williams PT, Bhanpuri NH, Peters AL, Campbell WW, et al. Effectiveness and safety of a novel care model for the management of type 2 diabetes at 1 year: an open-label, non-randomized, controlled study. Diabetes Ther 2018;9(2):583-612 [FREE Full text] [doi: 10.1007/s13300-018-0373-9] [Medline: 29417495]

16. Jeong JY, Jeon J, Bae K, Choi Y, Park K, Kim J, et al. Smart care based on telemonitoring and telemedicine for type 2 diabetes care: multi-center randomized controlled trial. Telemed J E Health 2018;24(8):604-613. [doi: 10.1089/tmj.2017.0203] [Medline: 29341843]

17. Battelino T, Danne T, Bergenstal RM, Amiel SA, Beck R, Biester T, et al. Clinical targets for continuous glucose monitoring data interpretation: recommendations from the international consensus on time in range. Diabetes Care 2019;42(8):1593-1603. [doi: 10.2337/dci19-0028] [Medline: 31177185]

18. Runge AS, Kennedy L, Brown AS, Dove AE, Levine BJ, Koontz SP, et al. Does time-in-range matter? Perspectives from people with diabetes on the success of current therapies and the drivers of improved outcomes. Clin Diabetes 2018;36(2):112-119 [FREE Full text] [doi: 10.2337/cd17-0094] [Medline: 29686449]

\author{
Abbreviations \\ BMI: body mass index \\ BP: blood pressure \\ CDCES: Certified Diabetes Care and Education Specialist \\ CGM: continuous glucose monitoring \\ HbA1c: glycated hemoglobin \\ HDL: high-density lipoprotein \\ LDL: low-density lipoprotein \\ RCT: randomized controlled trial \\ RT-CGM: real-time continuous glucose monitoring \\ T2D: type 2 diabetes \\ TIR: time in range \\ VDC: virtual diabetes clinic
}

Edited by G Eysenbach; submitted 07.07.20; peer-reviewed by D Rodbard, L Heinemann; comments to author $11.07 .20 ;$ revised
version received 20.07.20; accepted 23.07.20; published 28.08.20
Please cite as:
Majithia AR, Kusiak CM, Armento Lee A, Colangelo FR, Romanelli RJ, Robertson S, Miller DP, Erani DM, Layne JE, Dixon RF,
Zisser H
Glycemic Outcomes in Adults With Type 2 Diabetes Participating in a Continuous Glucose Monitor-Driven Virtual Diabetes Clinic:
Prospective Trial
J Med Internet Res 2020;22(8):e21778
URL: $\underline{\text { https://www.jmir.org/2020/8/e21778 }}$
doi: $\underline{10.2196 / 21778}$
PMID: $\underline{32856597}$


(C)Amit R Majithia, Coco M Kusiak, Amy Armento Lee, Francis R Colangelo, Robert J Romanelli, Scott Robertson, David P Miller, David M Erani, Jennifer E Layne, Ronald F Dixon, Howard Zisser. Originally published in the Journal of Medical Internet Research (http://www.jmir.org), 28.08.2020. This is an open-access article distributed under the terms of the Creative Commons Attribution License (https://creativecommons.org/licenses/by/4.0/), which permits unrestricted use, distribution, and reproduction in any medium, provided the original work, first published in the Journal of Medical Internet Research, is properly cited. The complete bibliographic information, a link to the original publication on http://www.jmir.org/, as well as this copyright and license information must be included. 